\title{
DETERMINING THE FIRE RATING OF CONCRETE STRUCTURES Case study of using a probabilistic approach and travelling fires
}

\author{
Tad-Song Kho ${ }^{\mathrm{a}}$, Florian M. Block ${ }^{\mathrm{b}}$, Thomas G. Lowry ${ }^{\mathrm{a}}$ \\ ${ }^{\text {a }}$ BuroHappold Fire Engineering, London, UK \\ ${ }^{\mathrm{b}}$ BuroHappold Fire Engineering, Frankfurt am Main, Germany
}

\begin{abstract}
As part of a refurbishment the height of a building in London is to be increased resulting in a change of the fire rating of the existing level from R60 to R90 as per prescriptive guidance. To investigate whether the inherent fire resistance of the structure would be sufficient a state-of-the-art probabilistic approach was adopted, with the approach extended to consider 2D heat-transfer to concrete elements. After determining the required reliability of the structure based on an acceptable risk level, a Monte-Carlo assessment was conducted. This considered for the proposed internal layouts and determined the range of input parameters to be randomly varied in order to define the required range of design fires analysed. The assessment demonstrated that the inherent structural fire resistance would provide sufficient structural reliability for the new use of the building and that no additional fire protection was required to the concrete frame.
\end{abstract}

Keywords: probabilistic design, travelling fires, Monte-Carlo, existing concrete building, integrated TASEF modelling

\section{INTRODUCTION}

Prescriptive fire resistance rating (FRR) to structures can be unnecessarily onerous as it is a generic solution to cover a wide range of buildings with little regard to actual structural behaviour of these buildings, each of which are unique; therefore it is not always the most appropriate solution. By adopting a holistic structural fire engineering (SFE) approach to buildings on a case-by-case basis, it can be demonstrated that a building can meet the life safety requirements whilst providing a FRR appropriate to the characteristics of the building such as occupancy type, building height and internal layout. Implementing an SFE approach also allows the application of state of the art knowledge in this field based on recent research work in place of traditional prescriptive design methods which may not necessarily be applicable today, where buildings are becoming increasingly more complex.

The paper describes the application of a performance based SFE approach to the refurbishment and extension of Wates House, an existing 6-storey concrete-framed building completed in the 1975 and has been home to The Bartlett School of Architecture in London, UK, in which large open plan design studio space being provided at multiple levels.
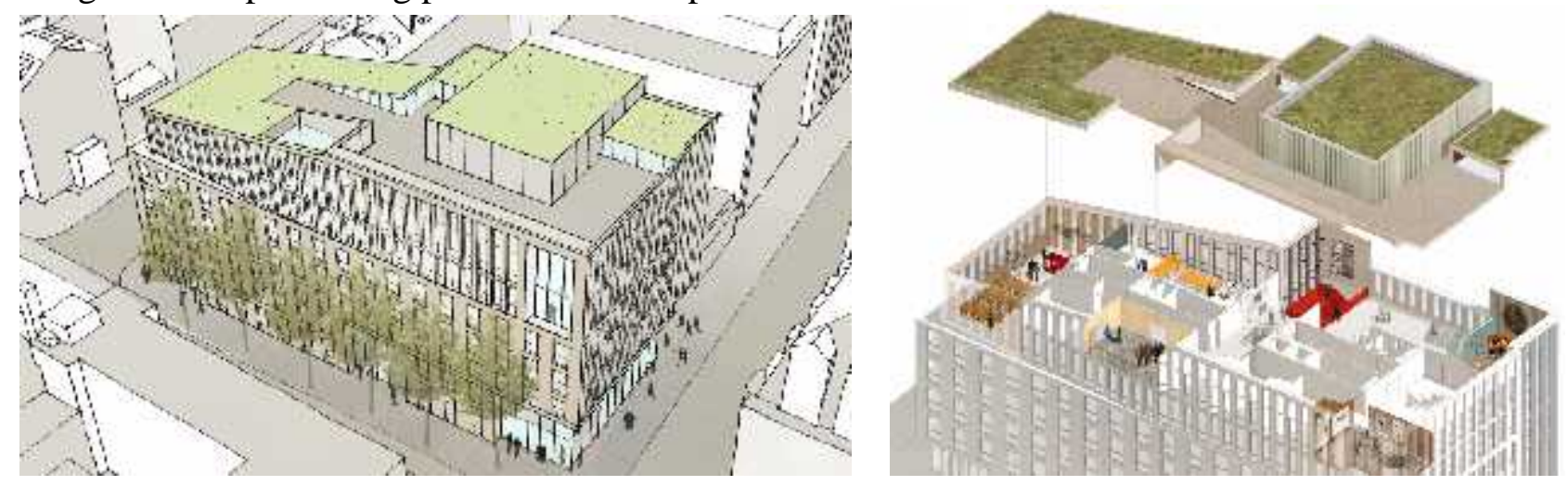

Fig. 1 Proposed refurbishment of Wates House (credit: Hawkins\Brown) 
The existing frame of the building is of reinforced concrete construction with the floor supported by a combination of concrete ribs and beam strips. The refurbishment and extension of the building involves replacement of the 5th floor and addition of a new $6^{\text {th }}$ floor using a steel-framed composite floor solution. The net addition of one floor brings the height of the building to approximately 20 metres, from a previous height of 16.7 metres. Survey carried out on the original concrete frame has shown that the minimum thickness cover of the concrete slab is $15 \mathrm{~mm}$, which is consistent with the design guidance at the time in providing 60 minutes fire rating for a building below 18 metres height (BRE, 2004). However, the increase in building height means that the fire rating of the unsprinklered building, after refurbishment, would need to achieve R90 based on the recommendations in Table 25 of BS9999 (BSI, 2008).

The increase in FRR means that the existing exposed concrete elements such as the columns, beams and slabs would need to be covered with fire board or similar passive fire protection to provide the extra level of fire protection. However, this would have significant implications in relation to cost, construction time and usable floor area in the building. As such, it is the intent to demonstrate that the inherent FRR of the existing concrete frame would provide sufficient reliability for the new use of the building without the need for additional fire protection to the existing frame. The added benefit would be that the new steel frame at the top two floor can also be fire protected to R60 instead of the prescribed R90 as per code requirements. Therefore this paper describes the SFE study carried out on the two forms of construction - steel and concrete.

\section{METHODOLOGY}

The general methodology adopted for this probabilistic study follows that of Law et al. (2014) with the exception that it has been adopted to determine the temperature of rebar within reinforced concrete sections in addition to steel sections. The methodology includes the following steps:

- Define the compartment and ventilation geometry of all fire compartments within the building;

- Prescribe amount of fire protection to structure; in this case cover to existing concrete structure is already known and steel will be prescribed with 60-minute fire protection;

- Simulation of a range of realistic design fires utilising the Monte Carlo method in order to obtain a range of gas temperature time curves within compartments;

- Detailed calculation of the heat transfer to the structural members from the already defined gas temperature time curves;

- Calculation of the temperature of the reinforcement in the reinforced concrete floors or the temperature of the steel members; and

- Determine the mechanical response of the structure due to the pre-determined thermal effects.

\section{ACCEPTANCE CRITERIA}

\subsection{Acceptable level of risk}

An acceptable level of risk is quantified following assumptions outlined by Law et al. (2014); readers are directed to their paper for more details about the approach. The risk is calculated as:

$$
\text { Risk }=h \times(1-r) \times h
$$

The quantifiable level of risk (Risk) in Eq. (1) is calibrated against Approved Document B (2000) assuming building height $(h)$ is 18 metres and required reliability $(r)$ of the building under fire as $80 \%$ (Kirby et al., 2004). The acceptable risk level is therefore calculated to be 64.8 . The required reliability of the refurbished Wates House, being 20 metres in height, becomes $84 \%$, meaning the building should be able to withstand $84 \%$ of fires simulated without structural failure occurring.

\subsection{Defining failure of structure}

Failure of the structure due to fire is assumed to be due to failure of a notional structural member. (Law et al., 2014). While the notion that the failure of individual members would lead to the global 
failure of the building is very often not realistic it is often considered as a conservative assumption. Analysing a selected few notional structural members is done on the premise that these results can be extrapolated to other parts of the structure which have a similar level of FRR.

The failure of the concrete structure is assumed to occur when the steel rebar of the notional floor structure reaches its limiting temperature. The limiting temperature of the rebar is taken as the peak temperature achieved when the concrete section is subjected to a Standard Fire for 60 minutes based on the $15 \mathrm{~mm}$ concrete cover required to meet the required FRR at the same historical period. By taking the average temperature within the rebar, the limiting temperature is calculated to be approximately $549^{\circ} \mathrm{C}$ as shown in the temperature profile in Fig. 2. By demonstrating that the average rebar temperature are below $549^{\circ} \mathrm{C}$ for $84 \%$ (see Section 3.1 ) of the potential fires, the inherent FRR of the concrete frame construction would be sufficient.

\begin{tabular}{|c|c|c|c|c|c|c|c|c|c|c|c|}
\hline 79 & 79 & 80 & 80 & 80 & 80 & 80 & 80 & 80 & 80 & 79 & 79 \\
\hline 85 & 85 & 85 & 85 & 85 & 85 & 85 & 85 & 85 & 85 & 85 & 85 \\
\hline 93 & 93 & 93 & 93 & 93 & 93 & 93 & 93 & 93 & 93 & 93 & 93 \\
\hline 103 & 103 & 103 & 103 & 103 & 103 & 103 & 103 & 103 & 103 & 103 & 103 \\
\hline 118 & 118 & 118 & 118 & 118 & 119 & 119 & 118 & 118 & 118 & 118 & 118 \\
\hline 138 & 138 & 139 & 139 & 139 & 140 & 140 & 139 & 139 & 139 & 138 & 138 \\
\hline 166 & 166 & 166 & 167 & 167 & 168 & 168 & 167 & 167 & 166 & 166 & 166 \\
\hline 201 & 201 & 202 & 203 & 204 & 204 & 204 & 204 & 203 & 202 & 201 & 201 \\
\hline 245 & 246 & 246 & 247 & 249 & 250 & 250 & 249 & 247 & 246 & 246 & 245 \\
\hline 299 & 299 & 299 & 301 & 303 & 305 & 305 & 303 & 301 & 299 & 299 & 299 \\
\hline 362 & 362 & 363 & 364 & 368 & 372 & 372 & 368 & 364 & 363 & 362 & 362 \\
\hline 438 & 438 & 439 & 439 & 443 & 458 & 458 & 443 & 439 & 439 & 438 & 438 \\
\hline 509 & 509 & 509 & 511 & 506 & 546 & 546 & 506 & 511 & 509 & 509 & 509 \\
\hline 592 & 592 & 592 & 591 & 598 & 552 & 552 & 598 & 591 & 592 & 592 & 592 \\
\hline 681 & 681 & 681 & 682 & 679 & 659 & 659 & 679 & 682 & 681 & 681 & 681 \\
\hline 784 & 784 & 784 & 784 & 781 & 772 & 772 & 781 & 784 & 784 & 784 & 784 \\
\hline 901 & 901 & 901 & 901 & 900 & 898 & 898 & 900 & 901 & 901 & 901 & 901 \\
\hline
\end{tabular}

\begin{tabular}{|c|}
\hline $\begin{array}{c}\text { Distance from bottom } \\
\text { surface [mm] }\end{array}$ \\
\hline 100.0 \\
\hline 93.2 \\
\hline 86.5 \\
\hline 79.7 \\
\hline 73.0 \\
\hline 66.2 \\
\hline 59.4 \\
\hline 52.7 \\
\hline 45.9 \\
\hline 39.2 \\
\hline 32.4 \\
\hline 25.6 \\
\hline 20.3 \\
\hline 15.0 \\
\hline 10.0 \\
\hline 5.0 \\
\hline 0.0 \\
\hline
\end{tabular}

\section{Surface exposed to fire}

Fig. 2 Temperature profile of concrete section when subjected to the Standard Fire for a period of 60 minutes

For the new steel frame construction, a typical secondary steel beam (UB 305x165x54) in the new construction is chosen as the notional fire-protected structural beam. For beams which are typically subjected to a three-sided fire exposure, a limiting temperature of $620^{\circ} \mathrm{C}$ is normally assumed when determining the required fire protection. Therefore the temperature of the notional beam should be less than $620^{\circ} \mathrm{C}$ in $84 \%$ of the potential fires in the proposed building.

Adopting the approach above in which the Standard Fire and a predetermined load ratio are used as the basis of determining the limiting temperature of the structural members can be considered dated. However, the approach establishes an equivalent level of safety to what had been commonly accepted at the time and is considered a more simplified approach without having the need to conduct the perhaps unnecessary and difficult task of conducting a full structural assessment to the existing structure to determine a more realistic limiting temperature. Nevertheless, the assessment can be used as the basis of more complex and holistic structural response modelling if required.

\section{PROBABILISTIC STUDY}

The Monte Carlo method is an algorithm that involves repeated random sampling to obtain the distribution of a probabilistic outcome. In this case the Monte Carlo method is applied to simulate a total of 10,000 possible design fires were simulated for any one analysis (Kirby et al., 2004) during which variables defining the fire scenarios are chosen at random within a defined distribution curve for input into the engineering calculations. This allows the probabilistic element of fire scenarios to be accounted for, which makes up for the shortcomings of traditional deterministic approach which does not account for the uncertainties that prevail in the real world.

The large open plan design studios in the proposed development means that it is likely for travelling fire to occur within the building in addition to the typical parametric fires, which would 
typically occur in smaller fire compartments. While the parametric fires will be defined in accordance with EN 1991-1-2 (BSI, 2002), the travelling fire methodology used in the analysis is based on recent studies by Stern-Gottfried and Rein (2012). While EN 1991-1-2 (BSI, 2002) suggests that the parametric fire curves are valid for compartments with floor areas up to $500 \mathrm{~m}^{2}$, a fifth of this value is conservatively used as the limit in this assessment. Therefore, it has been set that if a compartment area exceeds $100 \mathrm{~m}^{2}$ a travelling fire is assumed to occur with a compartment fire occurring if the compartment area is less than the threshold (Law et al., 2014).

A flow chart of the Monte Carlo analysis adopted in this case study is shown in Fig. 3. This has been programmed into Microsoft Excel, which is linked to TASEF (Wickstrom, 1979) - a software used to conduct the heat transfer analysis in the concrete section. The heat transfer to the steel section is conducted in accordance with EN 1993-1-2 (BSI, 2005).

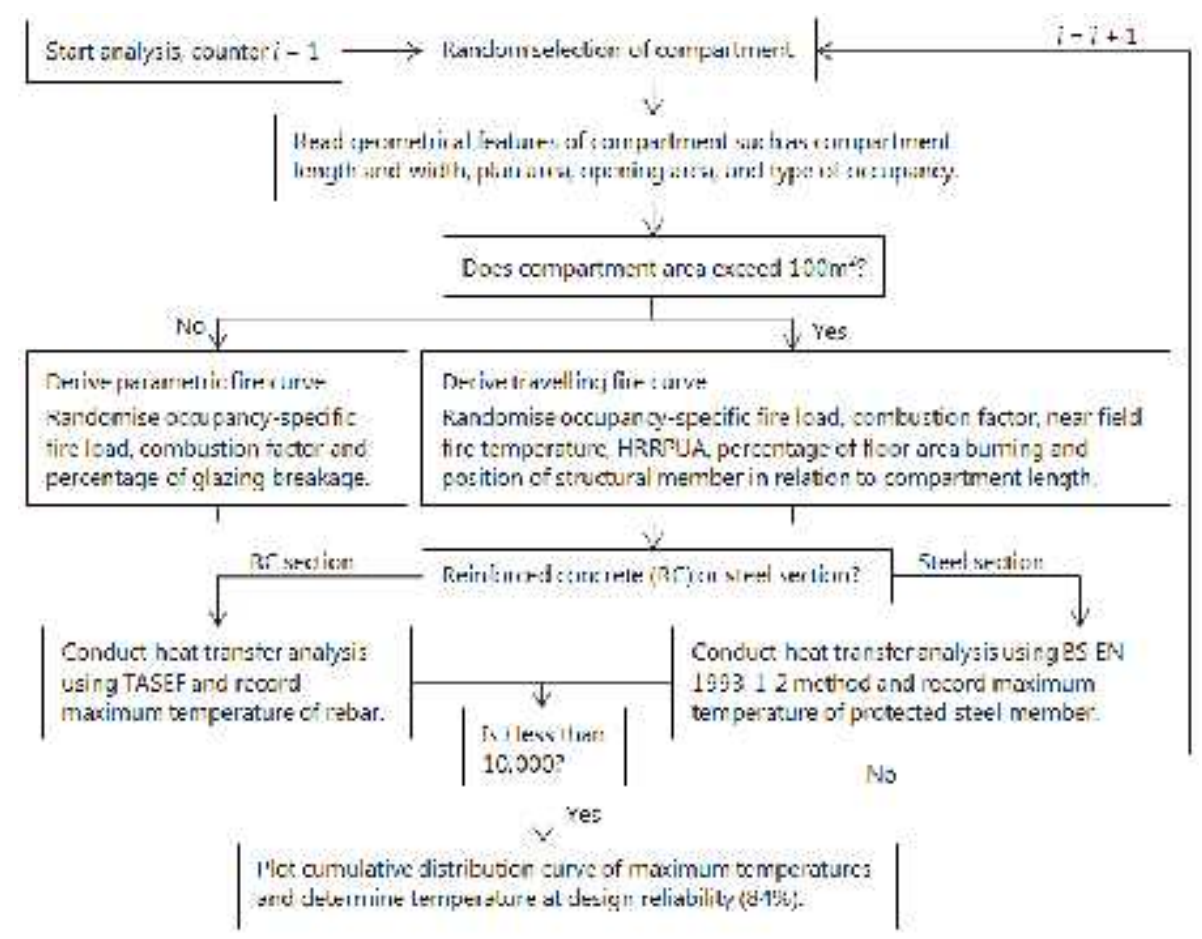

Fig. 3 Flow chart of Monte Carlo probabilistic assessment

Most of the parameters listed in Fig. 3, which are randomly selected from distribution curves are defined based on project experience due to the lack of experimental and statistical data for these parameters except the fire load density (FLD) (Kirby et al., 2004) (Law et al., 2014); see Fig. 4a. Due to the uncertainty of the distribution curves associated with certain parameters a sensitivity study has been carried out by changing the distribution curves of the ventilation and Heat Release Rate per Unit area (HRRPUA) relative to the base case, as shown in Fig. $4 b$ and $4 c$. A different size/configuration for each form of construction have also been investigated. In total 5 sensitivity cases in addition to the base case have been investigated for the concrete frame; a similar study have been carried on the steel frame.
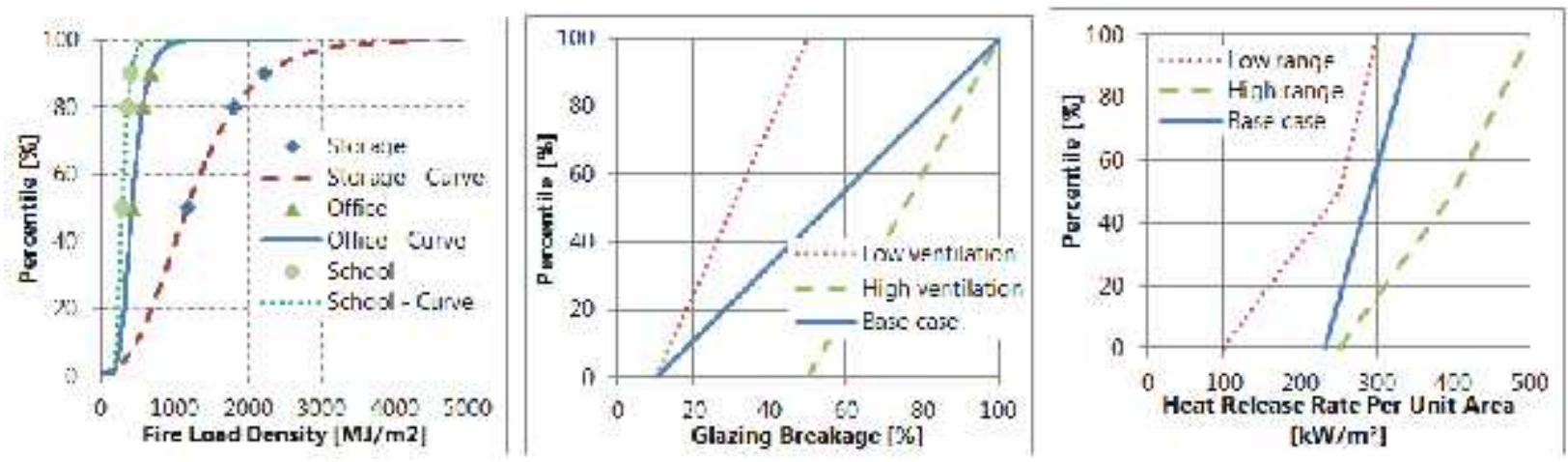

Fig. 4 Distribution curves of a) FLD (left), b) glazing breakage (middle) and c) HRRPUA (right) 


\subsection{Thermal Response of the Structure}

The design fires and corresponding rebar temperatures of a concrete section generated by the Monte-Carlo method for the base case are shown in Fig. 5 as a typical example. Only the first 255 design fires and rebar temperatures are plotted here due to software limitations. It can be observed that travelling fires tend to last for longer periods in comparison to parametric fires, generally resulting in higher rebar temperatures due to preheating of the concrete section by the far field of the fire before peaking when subjected to the near field temperature.
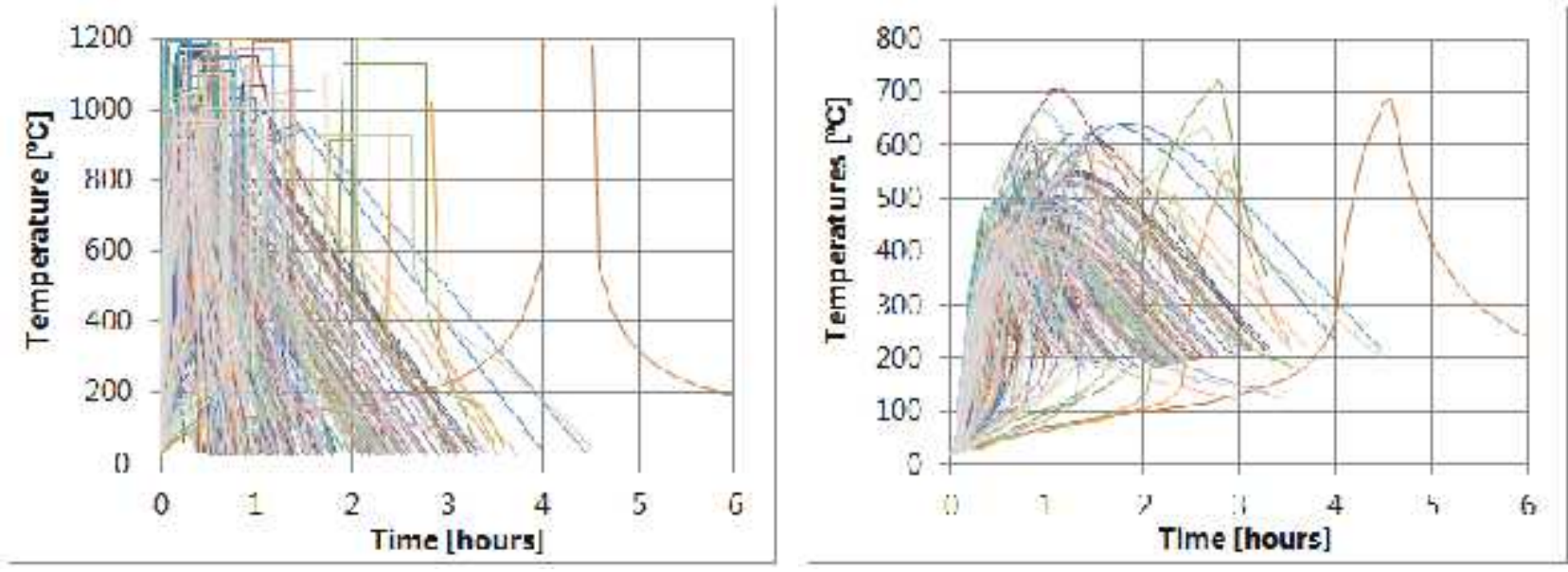

Fig. 5 Design fire and rebar temperature curves for base case of concrete section

\subsection{Cumulative distribution curve}

A cumulative distribution curve for the peak rebar temperatures of the base case can be plotted as shown in the left subfigure of Fig. 6. It can be seen that the required $84 \%$ design reliability corresponds with maximum rebar temperatures of approximately $527^{\circ} \mathrm{C}$, implying that $84 \%$ of total design fires analysed in proposed development do not exceed this temperature. All six cases are plotted alongside each other in the right subfigure of Fig. 6. The temperatures for the six cases ranges from $512-548^{\circ} \mathrm{C}$ at the $84^{\text {th }}$ percentile, with the worst case being the case with a low HRRPUA range. Having a lower HRRPUA means that the section tends to be heated for a prolonged period of time relative to the other cases in the travelling fires, resulting in higher temperatures. As the range of temperatures does not exceed the limiting temperature of $549^{\circ} \mathrm{C}$ defined in Section 3.2, it can be concluded that the existing concrete structure is capable of resisting the assumed range of possible fires while maintaining its structural reliability. The same conclusion can be drawn for the steel section in which the range of peak temperatures for the six steel section cases are below the $620^{\circ} \mathrm{C}$ limit define in Section 6.2. While the maximum temperature for the base case is $590^{\circ} \mathrm{C}$ at the 84 th percentile the six cases ranges from $569-619^{\circ} \mathrm{C}$ at the same percentile, with the worst case similarly being the case with a low HRRPUA range.
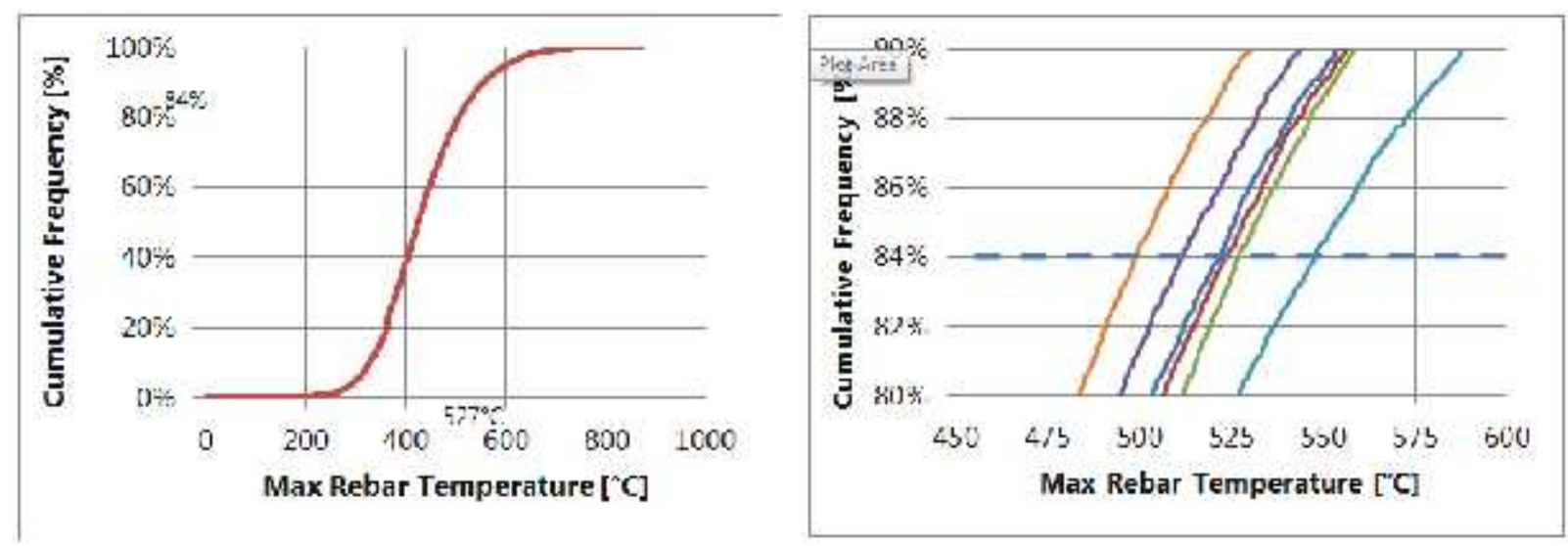

Fig. 6 Cumulative distribution curves of the rebar for the base case and the compilation for all six cases 
Robustness of the Monte Carlo assessment is ensured by conducting a sensitivity study to the concrete and steel section, which has shown that the solution is still below the limiting temperature. Thus by extrapolating the results to the other structural members, statistically it has been shown that the concrete section analysed in proposed building has sufficient inherent fire resistance to resist fires which are representative of the risks associated with the use and height of the building. The new steel construction, when provided with 60 minutes fire protection, is also shown to be able to resist the assumed range of fires related to the BS 9999 risk levels.

\section{FUTURE WORK}

More statistical data on the distribution curves of the fire input and a better understanding of the travelling fire phenomenon would increase the realism of the possible fires defined, although sensitivity studies help negate some of these shortcomings to a certain extent.

\section{CONCLUSIONS}

The assessment has demonstrated that the inherent FRR of the RC structure and the application of 60-minute fire protection to the new steel construction would provide sufficient reliability for the new use of the building; with this no additional fire protection would be required to the existing concrete frame. This leads to reduction in the construction programme, savings in cost and more net usable floor space for the students and faculty members in the architecture school. The SFE work has been approved by the approving authorities and its precedence acts as a "proof of concept", which can be theoretically applied to buildings of different height, occupancy risks and conditions (refurbished or new) where the approach could yield considerable benefits in relation to cost, construction time and usable floor area in the building. Therefore, the probabilistic approach described herein is a powerful tool which allows a bespoke approach in determining the appropriate fire resistance of a concrete and/or steel-framed building given the acceptable calculated risk.

\section{ACKNOWLEDGMENTS}

The authors would like to thank Hawkins\Brown and UCL for permission to use Wates House as a case study and to use their images for this paper.

\section{REFERENCES}

Approved Document B, 2000. Department of the Environment, Transport and Regions and Welsh Office. The Building Regulations - Part B. HMSO.

BRE (British Research Establishment), 2004. Lennon, T., Fire Safety of Concrete Structures: Background to BS 8110 Fire Design. Garston, Report BR 468.

BSI (British Standards Institution), 2002. Eurocode 1: Actions on structures: Part 1-2: General Actions Actions on structures exposed to fire. British Standards Institution. BS EN1991-1-2: 2002.

BSI (British Standards Institution), 2003. PD7974 - Application of fire safety engineering principles to the design of buildings - Part 1: Initiation and development of fire within the enclosure of origin (Sub-system 1). British Standards Institution.

BSI (British Standards Institution), 2005. Eurocode 3: Design of Steel Structures: Part 1-2: General Rule Structural Fire Design. British Standards Institution. BS EN1993-1-2: 2005.

BSI (British Standards Institution), 2008. Code of practice for fire safety in the design, management and use of buildings. London : British Standards Institution. BS9999:2008.

Kirby B. R., Newman G. M., Butterworth, N., Pagan, J. and English, C (2004). A new approach to specifying fire resistance periods. The Structural Engineer 84: p. 34-37

Law, A., Butterworth, N., Stern-Gottfried, J (2014). A Risk Based Framework for Time Equivalence and Fire Resistance, Fire Technology.

Stern-Gottfried, J.and Rein G (2012). Travelling fires for structural design-Part II: Design methodology. Fire Safety Journal 54 p. 96-112.

Wickstrom, U (1979). TASEF-2: A computer program for temperature analysis of structure exposed to fire. Lund : Lund Institute of Technology, Sweden. Report No. 79-2. 